\title{
LINFOMA CUTÂNEO PRIMÁRIO DE CÉLULAS T PERIFÉRICO E DOENÇA CELÍACA
}

Ana Isabel Duarte Moreira ${ }^{1 *}$, Nuno Menezes ${ }^{1},{\text { Paulo } \text { Varela }^{1} \text {, David Tente }}^{2}$, Edite Ferreira ${ }^{3}$, Mário Giesteira ${ }^{3}$, Joana Pestana ${ }^{4}$, Armando Baptista ${ }^{1}$, António Couceiro²

Trabalho realizado no Centro Hospitalar de Vila Nova de Gaia/Espinho, Portugal

\author{
*Correspondência: \\ Centro Hospitalar de Vila Nova de Gaia/Espinho \\ Serviço de Dermatologia \\ Rua Conceição Fernandes - Vilar de Andorinho \\ 4430-502 - Vila Nova de Gaia, Portugal
}

\section{INTRODUÇÃO}

A denominação linfomas cutâneos primários designa um conjunto de linfomas malignos que se manifestam com lesões cutâneas e sem evidência de envolvimento extracutâneo na altura do diagnóstico. A sistematização destes linfomas é difícil e por vezes controversa, existindo basicamente duas classificações: a da European Organization for Research and Treatment of Cancer (EORTC) e a da Organização Mundial de Saúde (World Health Organization-WHO). Após várias reuniões de consenso, foi possível formular uma classificação conjunta - a WHO-EORTC dos linfomas cutâneos, publicada em maio de 2005.

Um dos grupos de linfomas cuja definição era mais controversa, e que eram classificados de forma divergente nas anteriores classificações EORTC e WHO, era o grupo dos linfomas cutâneos de células T (LCCT) excluindo micose fungóide, síndrome de Sézary e linfomas cutâneos primários CD30. Este grupo, designado de linfomas citotóxicos, que representa menos de $10 \%$ dos LCCT e tem habitualmente um comportamento agressivo, era na realidade um grupo muito heterogéneo e no qual se tinham vindo progressivamente a individualizar novas categorias diagnósticas. Na nova classificação WHO-EORTC, dentro deste grupo, definiram-se como entidades com características clínico-patológicas perfeitamente distintas, o linfoma de células T subcutâneo tipo paniculite (LCTS) e o linfoma cutâneo de células NK/T tipo nasal, este último anteriormente reconhecido apenas na classificação WHO.1,2

Este caso foi classificado como linfoma cutâneo primário de células T periférico pelas suas características não permitirem a inclusão num subtipo de linfoma/leucemia de células $T$ mais bem definido.

A doença celíaca é um distúrbio autoimune que origina uma intolerância permanente ao glúten. Esta proteína encontra-se presente no trigo, centeio, cevada e aveia. ${ }^{3} \mathrm{~A}$ associação entre doença celíaca e determinados linfomas já há muito está estabelecida, sendo o linfoma de células T associado a enteropatia o modelo mais bem estudado. Pode-se mesmo afirmar que este tipo de linfoma é a principal neoplasia que acomete estes doentes. ${ }^{4}$ A doença celíaca é um distúrbio crônico relativamente comum, mas a relação exata entre esta doença e os outros tipos de linfoma está longe de ser totalmente compreendida. ${ }^{5}$

\section{Caso clínico}

Doente de 51 anos, sexo feminino, raça caucasiana, com doença celíaca confirmada há um ano, observada no Serviço de Otorrinolaringologia do CHVNGaia/Espinho em junho de 2006 por drenagem purulenta espontânea, abundante, pelo meato nasal médio direito. A doente esteve sempre apirética. Apresentava ainda placa eritematosa, dolorosa e edematosa, de bordos irregulares e mal definidos, com dimensões de $5 \times 6 \mathrm{~cm}$, com duas áreas centrais crostosas sugestivas de necrose ao nível da região malar direita (Fig.1), com cerca de três meses de evolução.

Dado não se observar melhoria clínica após vários ciclos de antibioterapia, a doente foi então internada no referido serviço com suspeita clínica de sinusite maxilar complicada, tendo sido submetida a duas drenagens cirúrgicas no bloco operatório. A tomografia computorizada (TC) realizada após a cirurgia mostrou o seio maxilar direito arejado com discreto espessamento da mucosa. A parede etmoidal e esfenoidal direita também estava espessada e observava-se edema das partes moles da hemiface direita. O estudo anatomopatológico do tecido retirado do seio maxilar direito não revelou estruturas de natureza neoplásica ou fúngica (com coloração do PAS), mostrando tratar-se de um processo inflamatório intenso com supuração e necrose.

\footnotetext{
1. Serviço de Dermatologia

2. Serviço de Anatomia Patológica

3. Serviço de Otorrinolaringologia

4. Serviço de Medicina Interna

5. Centro Hospitalar de Vila Nova de Gaia/Espinho. Vila Nova de Gaia, Portugal
} 
O diagnóstico de doença celíaca tinha então sido confirmado um ano antes. A doente apresentava diarreia aquosa persistente, emagrecimento súbito de $10 \mathrm{Kg}$ (IMC de 15), fadiga, anemia e diminuição da densidade mineral óssea confirmada por osteodensitometria. A endoscopia digestiva alta e a colonoscopia foram normais, contudo a biopsia da segunda porção do duodeno mostrou hiperplasia das criptas e atrofia vilositária total. A serologia da doença celíaca foi fortemente positiva - IgA antitransglutaminase de 35,3U (negativa se inferior a 20U) - e a videoendoscopia por cápsula mostrou alterações típicas de doença celíaca e ulceração no íleo distal, levantando a hipótese de jejunoileíte ulcerativa ou doença de Crohn concomitante. Foi instituída dieta sem glúten e deflazacort $6 \mathrm{mg} / \mathrm{dia}(0,3 \mathrm{mg} / \mathrm{Kg} /$ dia), com diminuição da frequência da diarreia e aumento de cerca de $2 \mathrm{Kg}$ de peso.

Por agravamento progressivo da lesão e persistência da má resposta aos antibióticos instituídos foi pedida colaboração de Dermatologia.

$\mathrm{Na}$ data da nossa observação, a doente apresentava placa eritemato-violácea de bordos mal definidos na região malar direita, com edema que se estendia até a pálpebra superior homolateral e dorso do nariz. No centro da lesão, duas áreas de necrose com fundo sero-hemático crostoso e bordos elevados, inflamatórios, mostravam tendência a confluir (Fig. 2).

Efetuou-se biopsia cutânea que revelou epiderme sem alterações dignas de registo e presença na derme média e profunda e transição para o tecido celular subcutâneo de infiltrado perivascular de células mononucleares de tamanho intermédio, com citoplasma relativamente escasso, mal delimitado e núcleos umas vezes de contorno irregular com cromatina grosseira e outras vezes arredondados com cromatina fina; nucléolos de tamanho pequeno ou intermédio. Observou-se ainda imagens de penetração e destruição de paredes vasculares pelas células referidas, bem como áreas focais de necrose (Fig. 3). 0 estudo histoquímico com os métodos de Ziehl-Neelsen, Grocott e Gram foi negativo. A marcação imunoistoquímia das células tumorais foi positiva para CD45, CD3 de superfície e focalmente para CD4 e CD8, sendo negativa para CD20, CD56, CD57, CD58 e CD30. A hibridização in situ para o EBER-1 foi negativa e 0 estudo por PCR revelou rearranjo dos receptores das células T sem perfil policlonal como fundo. Efetuou-se o diagnóstico de linfoma cutâneo primário de células $T$ periférico por exclusão dos outros tipos de linfoma cutâneo.

A biopsia da medula óssea, o medulograma e a imunofenotipagem do sangue periférico foram normais. A TC cervico-toracoabdomino-pélvica não revelou envolvimento extracutâneo. A TC cerebral e da face apenas mostrou eventuais lesões isquémicas e persistência das alterações previamente descritas em nível dos seios perinasais direitos.

Durante o internamento verificou-se um agravamento progressivo da lesão cutânea com aumento da área de necrose, envolvimento da órbita direita e posteriormente da pálpebra esquerda, bem como desvio dos ossos próprios e tecidos moles do nariz.

A doente faleceu com múltiplas complicações médicas, ainda antes de ter iniciado tratamentos de radioterapia e/ou quimioterapia. A família não esteve de acordo com a realização da autópsia para melhor esclarecer a situação clínica.

\section{Figura 1 - Placa inflamatória com área central ulcerada com cerca de três meses de evolução}

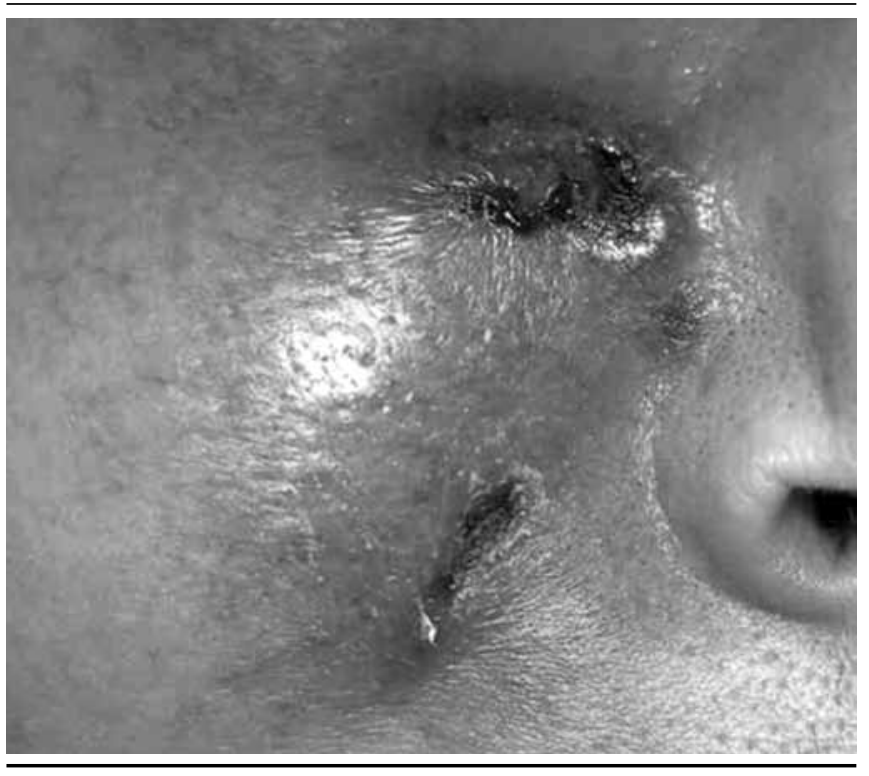

Figura 2 - Placa eritemato-violácea com área central necrótica

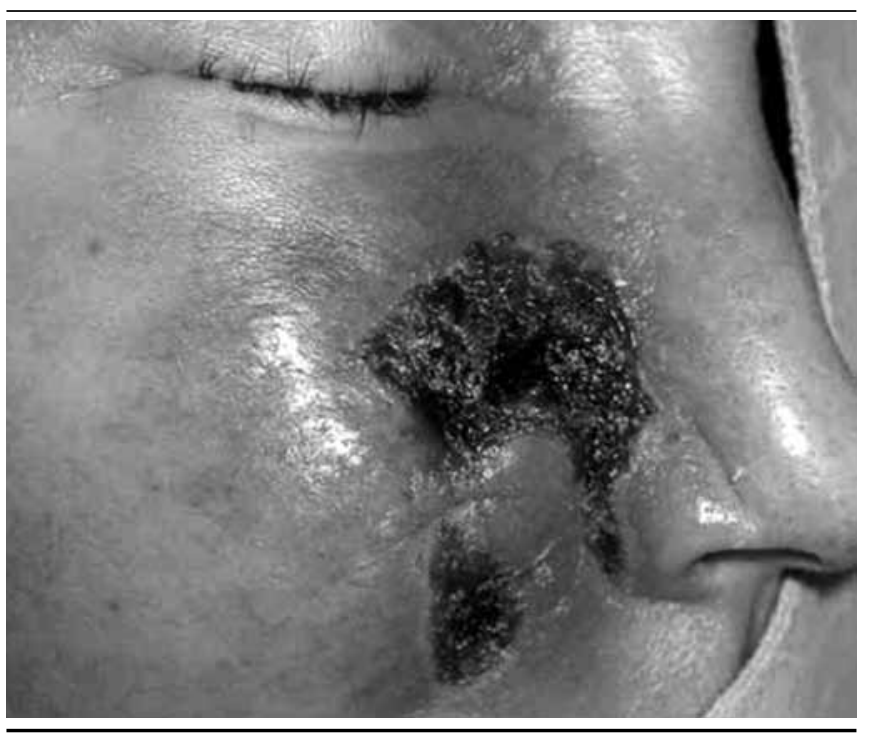

\section{Discussão}

A doença celíaca é uma doença autoimune multifacetada com associação a outros distúrbios imunológicos e com diversas manifestações extraintestinais. Os principais marcadores de susceptibilidade são o HLA-DQ2 e o HLA-DQ8. O diagnóstico baseia-se na biópsia da mucosa do intestino delgado com os achados típicos de atrofia vilositária e hiperplasia das criptas. Existem ainda autoanticorpos muito sensíveis e específicos, facilmente doseáveis, tais como autoanticorpos antiendomísio 


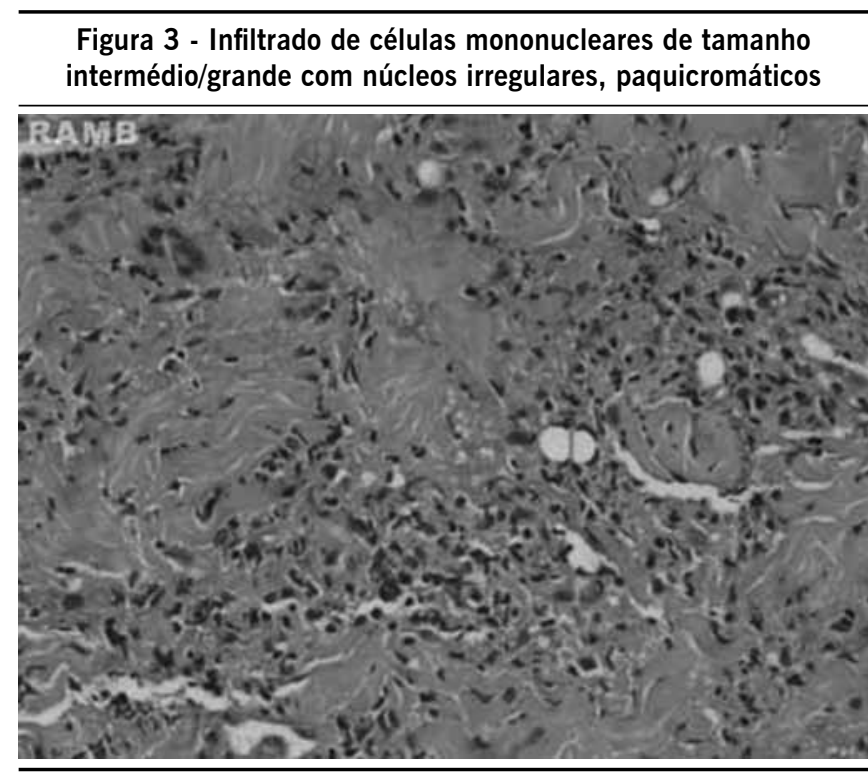

e antitransglutaminase tecidular. A prevalência desta doença na população europeia é de pelo menos $1 \%$. Os sintomas clássicos são a diarreia, os vômitos, a distensão abdominal e o atraso de crescimento na criança. Hoje em dia, a apresentação sob a forma de uma síndrome grave de má absorção constitui uma exceção. A doença manifesta-se sobretudo com sintomas ligeiros e não típicos e a idade do diagnóstico parece estar a aumentar. Estudos recentes referem que a sintomatologia gastrointestinal pode até estar ausente, sendo o diagnóstico suspeitado pelas manifestações extraintestinais (dermite herpetiforme, diminuição da densidade mineral óssea, amenorreia e menopausa precoce, distúrbios neurológicos e psicológicos, problemas reprodutivos, alterações hepáticas e cardíacas e diferentes doenças malignas). De acordo com um estudo recente, $2,8 \%$ de todos os doentes celíacos têm pelo menos uma neoplasia. A mais frequente e mais bem estudada é o linfoma de células $T$ associado à enteropatia do intestino delgado. Resulta sobretudo do diagnóstico tardio da doença e da má adesão à dieta sem glúten. ${ }^{3,5}$

Os linfomas cutâneos primários de células T periféricos representam um grupo heterogéneo e incluem todas as neoplasias de células T que não encaixam em nenhum dos outros subtipos de leucemia/linfoma de células T. ${ }^{6}$ É, portanto, um diagnóstico de exclusão. Apresentam habitualmente células neoplásicas grandes que constituem pelo menos $30 \%$ da população celular. A marcação imunoistoquímica para CD30 é negativa ou limitada a poucas células e casos raros podem coexpressar CD56. O prognóstico é mau, com uma sobrevida aos cinco anos inferior a $20 \%$. A quimioterapia com vários fármacos é o tratamento de escolha. ${ }^{1}$

A associação entre doença celíaca e linfomas já há muito está estabelecida e nos anos 80 afirmava-se que o risco relativo de desenvolver linfomas em doentes celíacos era extremamente alto. ${ }^{4}$ Contudo um estudo recente utilizando uma população de 12000 adultos com doença celíaca e dermite herpetiforme mostrou que apesar do risco global de contrair cancro estar aumentado, este era ainda assim frequentemente baixo e diminuía para próximo do risco da população geral com o tempo. ${ }^{7}$

Se a doença celíaca aumenta também o risco de desenvolver outros linfomas mais prevalentes, tais como linfomas de células B ou T não intestinais, ainda continua por esclarecer. ${ }^{8}$

Um estudo publicado em 2002 (Catassi et al.) pretende quantificar o risco de desenvolver linfoma não-Hodgkin nas mais diversas localizações, em doentes celíacos. Como principal conclusão salienta-se mais uma vez o risco aumentado de desenvolver linfoma não-Hodgkin especialmente de células $\mathrm{T}$, primariamente localizado ao intestino. A associação com linfomas não-Hodgkin com outra localização primária não ficou bem esclarecida e os resultados devem ser interpretados com cautela devido ao número reduzido da amostra. Interessante é a hipótese levantada de que o aparecimento da malignidade seja o fator que precipita a transformação de uma doença celíaca silenciosa para uma forma clinicamente manifesta. A doença celíaca seria diagnosticada primeiro e o linfoma não-Hodgkin quase logo de seguida. ${ }^{3}$ Apesar de tudo, parece que o diagnóstico precoce de doença celíaca, por exemplo através de testes de rastreio serológico, não vai reduzir significativamente o aparecimento de linfomas não-Hodgkin na população geral e como tal não se preconiza a sua realização. ${ }^{3}$

Um estudo com 11650 doentes (Smedby et al., 2005) pretendeu estimar a distribuição e o risco dos diferentes subtipos de linfomas na doença celíaca. Este foi o primeiro estudo em grande escala que demonstrou que a associação entre doença celíaca e linfomas malignos não se limita apenas ao linfoma intestinal, mas também inclui outros tipos de linfomas não-Hodgkin T e sobretudo B, fora do trato gastrointestinal. Pela primeira vez foi demonstrado que a doença celíaca está associada a uma grande variedade de linfomas malignos, e como tal pode ser um modelo do potencial linfomagénico associado à autoimunidade e à inflamação crônica. ${ }^{8}$

São necessários mais estudos que apoiem esta associação e não existem dúvidas que a descoberta do modo exato de herança da doença celíaca e dos genes envolvidos no desenvolvimento de neoplasias vai com certeza clarificar esta associação no futuro. ${ }^{4}$

Este caso pode representar apenas uma coincidência ou ser de fato a expressão de um aumento de risco de linfoma não intestinal nos doentes celíacos, corroborado no presente caso pela relação temporal importante entre as duas doenças. Destaca-se então a presença simultânea de duas patologias raras que podem ou não pertencer ao mesmo espectro de doença.

Um artigo recente mostra que o diagnóstico diferencial de alterações intestinais deve ser cuidadosamente abordado, uma vez que alterações não neoplásicas (doença celíaca, sprue refratário e infiltração reativa de células T) podem mimetizar linfomas $\mathrm{T}$ intestinais ad initium ${ }^{9}$.

\section{Agradecimentos}

Os autores agradecem ao Prof. Rui Henrique do Instituto Português de Oncologia do Porto a realização da hibridização in situ para o EBER-1 e ao Dr João Rodrigues do Hospital Geral de Santo António, a pesquisa do rearranjo de receptores de células $\mathrm{T}$. 


\section{REFERÊNCIAS}

1. Slater DN. The new World Health Organization-European Organization for Research and Treatment of Câncer classification for cutaneous lymphomas:a practical marriage of two giants. Br J Dermatol. 2005;153:874-80.

2. Vale E, Pereira B, Silva R, Bordalo O. Linfoma cutâneo de células NK/T tipo nasal. Soc Portuguesa Dermatol Venereol. 2006;64:377-87.

3. Mustalahti K. Unusual manifestations of Celiac disease. Indian J Pediatrics. 2006;73:711-6.

4. Catassi C, Fabiani E, Corrao G, Barbato M. Risk of non-Hodgkin Iymphoma in celiac disease. JAMA. 2002;287:1413-9.

5. Kumar P. Celiac disease and Iymphoma. Eur J Gastroenterol Hepatol. 2006:18:131-2.

6. Kim YH, Willemze R, Pimpinelli N, Whittaker S, Olsen EA, Ranki A, et al. TNM classification system for primary cutaneous lymphomas other than mycosis fungoides and Sézary syndrome: a proposal of the International Society for Cutaneous Lymphomas (ISCL) and the Cutaneous Lymphomas Task Force of the European Organization of Research and Treatment of Cancer (EORTC). Blood. 2007;110:479-84
7. Askling J, Linet M, Gridley G, Halstensen TS, Ekstrom K, Ekbom A. Cancer incidence in a population-based cohort of individuals hospitalised with celiac disease or dermatitis herpetiformis. Gastroenterology. 2002; 123:1726-9.

8. Smedby KE, Akerman M, Hildebrand H, Glimelius B, Ekbom A, Askling J. Malignant lymphomas in coeliac disease: evidence of increased risks for lymphoma types other than enteropathy-type T cell lymphoma. Gut. 2005;54:54-9.

9. Muram-Zborovski T, Loeb D, Sun T. Primary intestinal intraepithelial natural killer-like T-cell lymphoma: case report of a distinct clinicopathologic entity. Arch Pathol Lab Med. 2009;133:133-7.

Artigo recebido: 18/01/09

Aceito para publicação: 22/04/09 